\title{
Remediaton of pesticide-polluted River using Anabaena and Nostoc spp.
}

\author{
$*^{1}$ Williams, Janet Olufunmilayo And Youngtor, Tuakabari Precious \\ Department Of Microbiology, Rivers State University, Port Harcourt, Nigeria. \\ *Corresponding Author: Williams
}

\begin{abstract}
Cyanobacteria are phototrophic aquatic microbes that are found in various environments and can reproduce rapidly either heterotrophically or chemoheterotrophically. Pesticide-pollutants are released into water bodies as a method of disposal. Bioremediation is considered an efficient and environmentally safe technology for inexpensive decontamination of such environments. Cyanobacteria species investigated in this study were highly beneficial in the remediation of the pesticide-polluted River. The Cyanobacteria isolated were identified as Anabaena and Nostoc species using Abattoir effluent and Aquaculture water from Ogoniland. Temperature, $p H$, phosphate and nitrate enhanced the growth of these organisms in the polluted environments with varying concentrations of pesticide $\left\{\operatorname{Nostoc}\left(N_{1} 4 \%, N_{2} 40 \%, N_{3} 80 \%\right)\right.$, Anabaena $\left(A_{1} 4 \%, A_{2} 40 \%, A_{3} 80 \%\right)$, Anabaena and Nostoc $\left(A N_{1} 4 \%, A N_{2} 40 \%, A N_{3} 80 \%\right)$. The microbiological analysis showed that $80 \%$ mixed culture $\left(A_{3}\right)$ had higher microbial counts especially on day 7 , which could be due to the presence of a mixed consortium of organisms and nutrients (Nitrogen and Phosphorus). The effectiveness of the Cyanobacteria used in the analysis was in the following descending order: $80 \% A N_{3}>40 \% A N_{2}>4 \% A N_{1}>80 \% N_{3}>80 \% A_{3}>$ $40 \% \mathrm{~N}_{2}>40 \% \mathrm{~A}_{2}>4 \% \mathrm{~N}_{1}>4 \% \mathrm{~A}_{1}$. From the student $\mathrm{T}$ test table, $A N_{3}(80 \%$ mixed culture) was more effective and capable of remediating the pesticide-polluted environment. The analysis of variance (ANOVA) showed that at 95\% confident level the significant differences among the samples varied in their ability to remediate the environment. Pollutant was removed by all the species, either as individuals or in a mixed consortium at all concentrations. Results established high removal efficiencies of the investigated species for the removal of the target contaminant which were species and contaminant-dependent. The contaminants removal efficiency (RE) percentage of cyanobacterial species ranged between 76.3 and $100 \%$ for $4 \%$ pesticide concentration, $83.9 \%$ and $99.9 \%$ for $40 \%$ concentration. Mixed culture (Anabaena and Nostoc (AN)) RE percentages ranged between 99.5 and $100 \%$ at $4 \%$ while at $40 \%$, the RE percentage ranged between 95.9 and $99.9 \%$ and at $80 \%$ pesticide concentration, it ranged between 91.7 and 100\%. Results obtained stipulate the potential of natural resources as proficient mediators for pollution control.
\end{abstract}

Keywords: Anabaena spp, Nostoc spp, pesticide-polluted environment, remediate.

\section{Introduction}

Cyanobacteria are common aquatic phototrophic microorganisms that are probably one of the most abundant components of biomass on our planet (Sorkokh et al., 1992). They thrive under a variety of extreme conditions where the abundance and activities of grazing organisms is limited and can form mats (blooms) (Kalavithi et al., 2001).

Cyanobacteria otherwise known as "blue-green algae" can reproduce rapidly under the right conditions either heterotrophically or chemoheterotrophically by using artificial light source to form harmful algal blooms (HABs) often referred to as cyanoHABs. CyanoHABs can take multiple shapes, forms and sizes; they may occur as unicellular or in groups as colonies or straight, coiled or twisted filaments that are clearly visible to the human eye (Pearl and Paul, 2012).

Many chemicals are released into the water bodies either as a method of disposal or as a consequence of the technology of the utilization, in particular, use of pesticide that are toxic or contain toxic contaminants (Alexander, 1994). Pesticides are substances that are designed to kill biological organisms including weeds, insects, etc. Their low biodegradability has classified these chemicals as persistent toxic substances (Tayade $e t$ al., 2013).

Bioremediation is considered as an efficient and environmentally safe technology for inexpensive decontamination of polluted systems (Yoo et al., 1995). The work of Tiens (2002) indicated that application of cyanobacteria showed immense potential in the remediation of polluted environments. Nostoc and Anabaena species co-metabolize the pesticide (Fleming and Haselkorn ,1994). Cyanobacteria have been shown to be 
highly effective as accumulators and degraders of different kinds of environmental pollutants, including pesticide (Megharaj et al., 1994).

Temperature and $\mathrm{pH}$ are important environmental parameters that influence the degradative process of pesticide pollution. These parameters influence the structure and physiology of existing microbial communities and result in change in physical and chemical properties of pollutant (Solubility and Viscosity) including the diversity; the metabolic potential of degrading bacteria is considered to decrease as environmental conditions become more extreme (Margein and Schinner 2001). In addition, carbon dioxide, organic matter, alkalinity, nitrates and phosphates are factors important in determining the distribution of Cyanobacteria (Podda et al., 2000). The regular monitoring and control of pesticide pollution is very essential because of the risk posed on our natural environment. The aim of this study was to determine the effectiveness of Cyanobacteria (Anabaena and Nostoc spp) in remediating a pesticide-polluted River water in ogoniland.

\section{Sample Collection}

\section{Materials And Methods}

Abattoir effluent and Aquaculture water samples were collected from Eagle island abattoir in Port Harcourt and Wii Yeghe River in Gokana Local Government Area respectively both in Rivers State. They were taken to the Microbiology laboratory, Rivers State University of Science and Technology, Port Harcourt for analysis.

\section{Bacteriological Analyses}

Single cell technique was used for the isolation of the Cyanobacteria in the sample (Burris, 2010). An aliquot of the sample was placed on a clean glass slide using sterile one milliliter $(1 \mathrm{ml})$ Pasteur pipette, covered with cover slip and viewed under x10 magnification of the microscope. The process was continued until the Cyanobacteria species were properly identified by their morphological characteristics. Prior to bioremediation of the pesticide-polluted River water, plating on bacterial nutrient medium (nutrient agar, Difco, UK) was done and incubation at $30^{\circ} \mathrm{C}$ for 1 week. Only axenic cultures, either uni- or multi-algal species were used.

\section{Remediation bioassay}

The selected species were inoculated individually or as mixtures into 50-ml culture medium and incubated for 1 week until heavy growth was obtained. For each species, as well as for the mixed culture, nine flasks $(100 \mathrm{ml}$ of sterilized modified Cyanobacterial medium in $250-\mathrm{ml}$ conical flasks) were prepared and sterilized. Each of the nine flasks was inoculated with $5 \mathrm{ml}$ of the 1-week dense individual Cyanobacterial suspensions, or with multiple species in the case of the mixed culture, incubated under the previously mentioned conditions and left to reach mid-late log phase of growth (E10 days).

\section{Growth Monitoring}

The pure cultures of Nostoc and Anabaena species were obtained and transferred by using sterile wire loop into the test tubes containing normal saline until turbid. About $5 \mathrm{ml}$ of each sample was taken by using sterile pipettes and emptied into the conical flasks with varying concentrations of pesticides $(4 \%, 40 \%$ and 80\%).A mixed consortium of Nostoc and Anabaena was also used as well as the single cultures in the pesticide polluted environments. Growth was monitored to determine the stimulatory or inhibitory effect of pollutants on the tested Cyanobacterial species (their sensitivity or resistance) in order to define the most resistant and promising bioremediation species.

The abattoir effluent (which served as growth nutrient ) (4\%,8\% and 12\%) was emptied into nine(9) conical flasks containing $250 \mathrm{ml}$ of river water polluted with a pesticide (Chloview) in a ratio of 4:40:80 and labeled $\mathrm{N}_{1}-\mathrm{N}_{3}$ for Nostoc, and $\mathrm{A}_{1}-\mathrm{A}_{3}$ for Anabaena, $\mathrm{AN}_{1}-\mathrm{AN}_{3}$ for mixed culture(Anabaena and Nostoc). Appropriate controls were also set up, containing only Nostoc (Control Oa), Anabaena species (Control Ob) and Mixed Culture (Anabaena and Nostoc spp) (Control Oc).

After the sample preparation, they were bloomed for two weeks under natural source of light (sunlight). The flasks were intermittently shaken three times daily to enhance growth by preventing sedimentation of the bacteria and thermal stratification which involves gas exchange between culture medium and air to ensure that cells of the population were equally exposed to light and nutrients and were left to reach mid-late log phase of growth.

\section{Determination of Cyanobacteria Concentration}

From the conical flasks containing Nostoc ,Anabaena spp. as well as for the mixed consortium (AN1, AN2,AN3 )with varying concentrations (4\%, $40 \%$ and $80 \%$ respectively), optical density was determined. About $5 \mathrm{ml}$ of samples were used and the spectrophotometer was set at $480 \mathrm{~nm}$. About $1 \mathrm{ml}$ of the blank (sterile) was transferred into a polystyrene cuvette using sterile technique to blank the spectrophotometer. Then each 
culture was transferred using sterile pipette into labeled cuvette and the optical density was read from the spectrophotometer. The optical densities of the controls ( $\mathrm{Oa}, \mathrm{Ob}$ and $\mathrm{Oc})$ were determined.

\section{Physicochemical Parameters of the Samples}

The physicochemical parameters were measured using standard analytical procedures (AOAC, 2000). The $\mathrm{pH}$ meter used was pocket-sized HANA pHep + HI 98108 with automatic temperature compensation. Total organic carbon was determined by dichromate wet oxidation method of Walkley and Black as modified by Dhyan et al., (1999). Nitrate content was determined using the macro Kjeldahl digestion method of Brady and Weil (1999) and available phosphorus was determined using the method reported by Olsen and Sommers (1982). Sulphate was determined using the turbidometric method. Standard methods were used for the determination of Dissolved Oxygen (DO), Biochemical Oxygen Demand(BOD) and Chemical Oxygen Demand(COD) (AOAC,2000).

\section{Statistical Analysis}

Results were subjected to statistical analysis employing the student t-test at 95\% probability levels using SPSS (Version 14.0) statistical package and Analysis of variance (ANOVA).

\section{Results and Discussion}

The results of the microbiological analysis of the pesticide polluted water with varying concentrations on figure 1 below showed steady increase in the optical densities of all the samples.

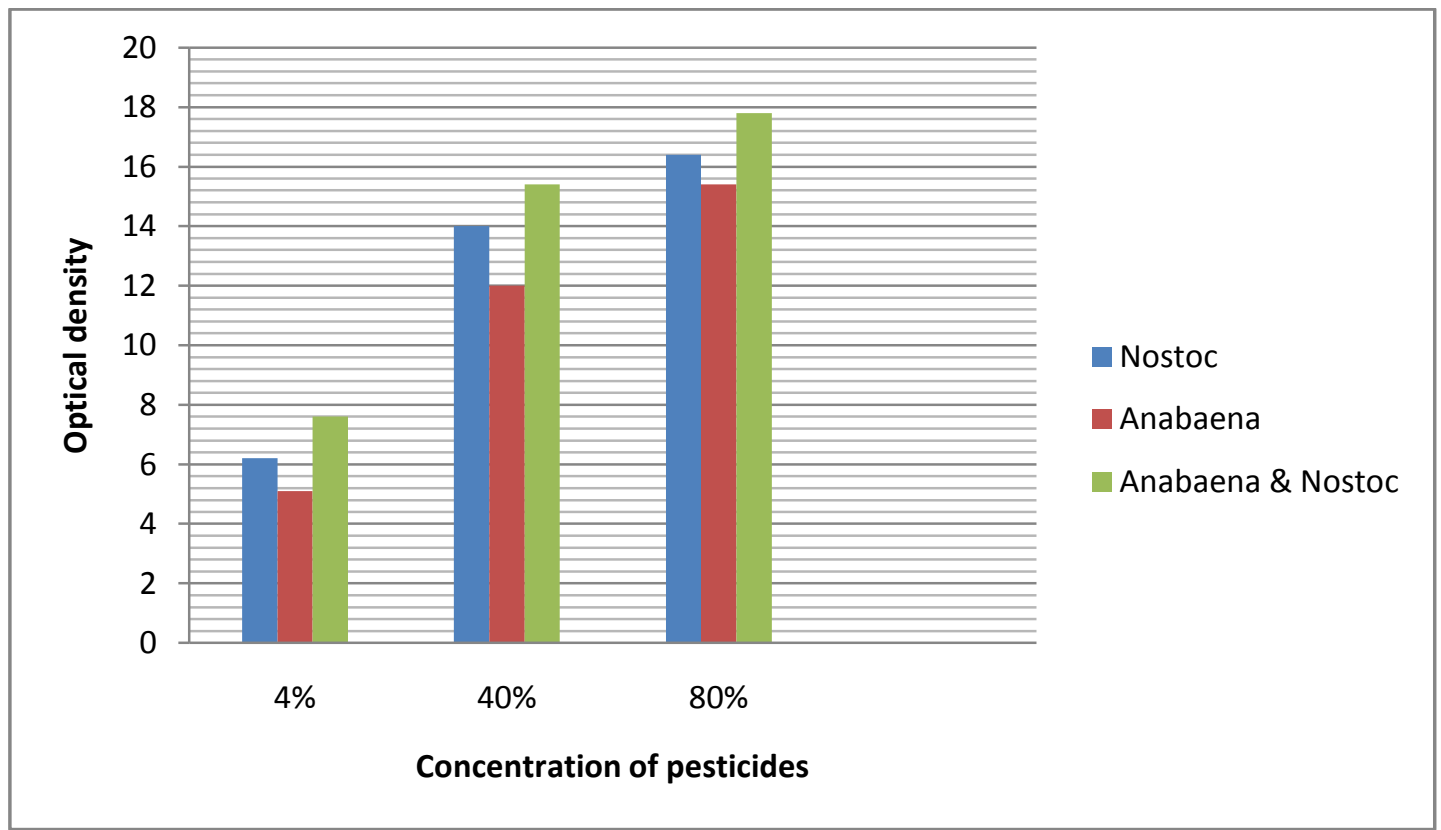

Fig. 1: Microbiological Analysis of pesticide polluted water with varying concentrations of pesticide.

The mixed culture $\left(\mathrm{AN}_{3}\right)$ had the highest growth rate due to the presence of chlorophyll, elevated concentration of oxidizable organic matter and trace dissolved oxygen. Considerable amounts of nitrate and phosphate in all the effluents investigated were probably the factors favoring the growth of Cyanobacteria (AOAC, 2000).

Table 1 below shows the physicochemical analysis of abattoir effluent and aquaculture water used in the study.

Table 1: Physicochemical parameters of abattoir effluent and aquaculture water

\begin{tabular}{|l|c|c|}
\hline Parameters & Abattoir effluent & Aquaculture water \\
\hline & & 8.1 \\
\hline Nitrate $(\mathrm{mg} / \mathrm{l})$ & 10 & 29.0 \\
\hline Temperature $\left({ }^{\circ} \mathrm{C}\right)$ & 26.2 & 20 \\
\hline Phosphate $(\mathrm{mg} / \mathrm{l})$ & 27 & 12 \\
\hline Sulphate $(\mathrm{mg} / \mathrm{l})$ & 12 & 7.90 \\
\hline $\mathrm{pH}$ & 7.13 & 0.15 \\
\hline Total Organic Carbon & 0.17 & 35 \\
BOD(mg/l) & 45 & 260 \\
COD(mg/l) & 278 & 1.0 \\
DO(mg/l $)$ & 1.2 & \\
\hline DOI: $10.9790 / 2402-1107017176$ & www iosrjournals.org & $73 \mid$ Page \\
\hline
\end{tabular}

DOI: $10.9790 / 2402-1107017176$

www.iosrjournals.org

73 | Page 
The microbiological analysis showed that the total cyanobacterial counts in fig. 1 were higher in the mixed culture $\left(\mathrm{AN}_{3: 80 \%}\right.$ ). The high counts could be due to the mixed cultures (Anabaena and Nostoc spp.) or the nutrients (nitrogen and phosphorus) that favored the Cyanobacterial growth (Ekundayo et al., 2010).

The $\mathrm{pH}$ of 7.13-7.90 observed in this study was within permissible limit (WHO, 2004). The temperature values ranged from $26.2-29^{\circ} \mathrm{C}$ for all samples. Increase in temperature must have been due to reduction in dissolved oxygen in the polluted environment (Ekundayo et al., 2010). High values of BOD, COD, phosphates and nitrates with very low DO favored the growth of Cyanobacteria than any other algae (Venkateswarlu, 1976). This concurred with the studies of Jeganathan (2006) and Haande (2008) in different industrial waste water.

In this study, the effluent and aquaculture water showed a substantial quantity of nitrate and phosphate with elevated level of BOD and COD as well as very low DO level (Ebtesam, 2008; Larsson et al., 2009).

The indigenous Cyanobacteria of both abbatoir effluent and aquaculture water were found to be enhanced degraders of pollutant. They were highly efficient in the degradation of the three concentrations used in this study.

Growth and biodegradation capabilities were affected by species of microorganisms, pollutant concentration, time of exposure and application as single or mixed cultures. Even at high levels of concentration $(80 \%)$, the pollutant (pesticide) exhibited excellent removal capabilities although it was thought that increasing pollutants concentration up to $10 \mathrm{ppm}$ would suppress the metabolic activities of all species. About $80 \%$ pesticide stimulated the capabilities of these species more efficiently than $4 \%$, leading to a much higher Removal Efficiency (RE) percentage at $80 \%$ in almost all cases. Removal was attributed to biodegradation, bioaccumulation or both though with different ratios. Within the first 2 days of analysis, high level of RE percentage was achieved by almost all the species studied. Increase in RE percentage was observed for the experimental species and on the $4^{\text {th }}$ day, the maximum was reached then a slight decline was observed at about the 7th day (Figures 2a,b and c). This could be as a result of adaptation of the wild species and appearance of mutants, which reach maximum RE percentage at about the 4 th day.

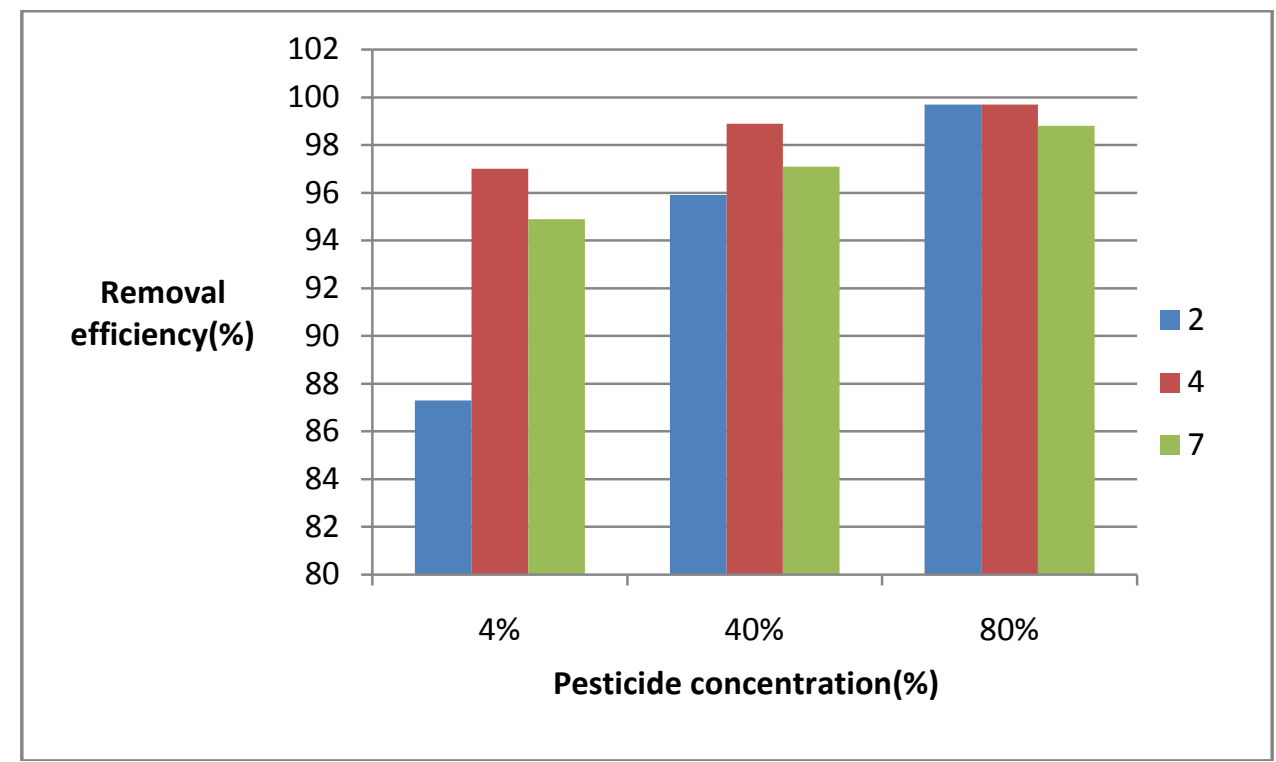

Fig.2a: Removal efficiency (\%) of Nostoc spp in Pesticide polluted water 


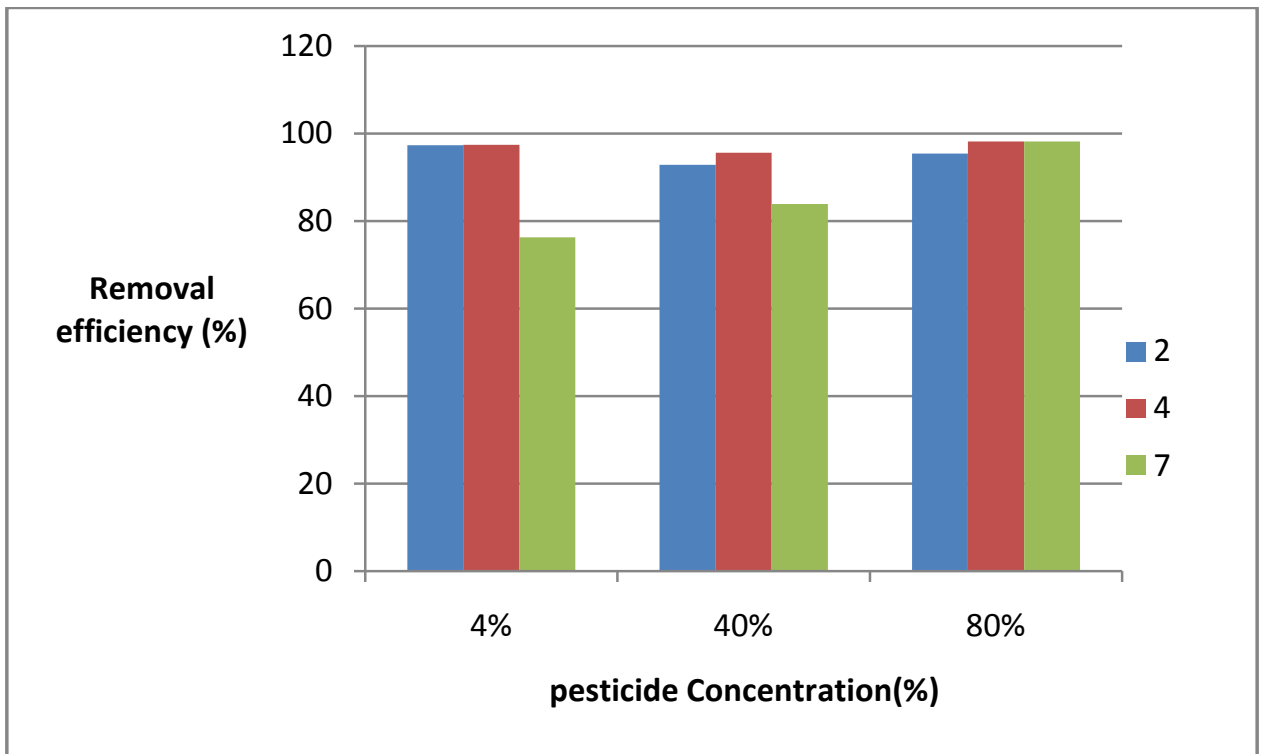

Fig.2b: Removal efficiency (\%) of Anabaena spp in Pesticide polluted water

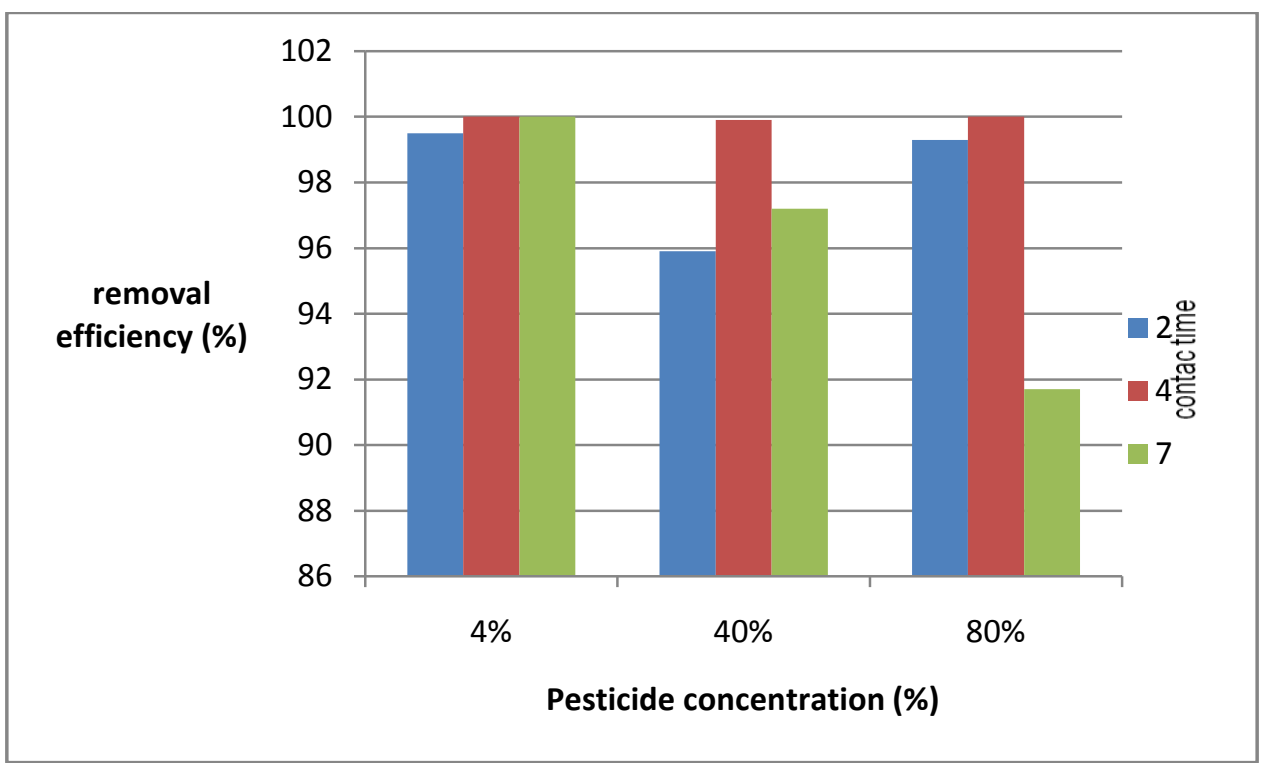

Fig.2c: Removal efficiency (\%) of Mixed Culture) Anabaena and Nostoc spp in Pesticide polluted water

Mixed culture (RE) percentages ranged between 99.5 and $100 \%$ at $4 \%$; for $40 \%$ concentration of pollutant, \% RE was between 95.9 - 99.9\% while at 80\%, \% RE ranged between 91.7 - 100\% (Fig. 2c). There was difference in the rate of pollutants removal from the medium. The analysis of variance (ANOVA) of the total cyanobacterial count in the samples showed that $\mathrm{AN}_{3}$ had the highest colonies count. The effectiveness of the cyanobacteria used in this analysis was in the following descending order: $80 \% \mathrm{AN}_{3}>40 \% \mathrm{AN}_{2}>4 \% \mathrm{AN}_{1}$, $80 \% \mathrm{~N}_{3}>80 \% \mathrm{~A}_{3}>40 \% \mathrm{~N}_{2}>4 \% \mathrm{~N}_{1}>4 \% \mathrm{~N}_{1}$. This concurred with the Students T-test which also showed that $\mathrm{AN}_{3}$ was more effective and capable of remediating the pesticide-polluted environment.

\section{Conclusion}

Abattoir effluent and Aquaculture water are sources of essential nutrients and media for the cultivation of cyanobacteria. This formulation encouraged effective growth of Cyanobacteria as well as rich primary productivity. The findings in this study are very important regarding the realistic utilization of Cyanobacteria species (Anabaena and Nostoc) in large-scale. From the feasibility and economic viewpoint, coupling RE with fast flow rate could be used in large scale bio treatment of effluents. Cyanobacteria species investigated in this study are extremely valuable bioremediation tools for in-situ and off-site elimination of pollutants. 


\section{References}

[1]. Alexander, M. (1994).Biodegradation and Bioremediation.San Diego, CA: Academic Press

[2]. AOAC (2000).Method of Analysis $14^{\text {th }}$ edn, Association of official Analytical chemists, Arington, VA., 503 - 515.

[3]. Brady, N.C. and Weil, R.R. (1999) The nature and properties of soils. $12^{\text {th }}$ edition . Upper Saddle River, NJ: Prentice Hall, inc. 881

[4]. Burris (2010). Single-cell analysis and isolation for microbiology and biotechnology: method and application. Appl Microbiol Biotechnol. 86(5):1281-92.

[5]. Dhyan,S., Chhonkar, P.K. and Pandey, R.N. (1999) Soil, Plant and water analysis- A method manual. Indian Agricultural Research Institute, New Delhi.

[6]. Ebtesam E-B (2008). Treatment of mixed domestic- industrial wastewater using cyanobacteria. J. Ind. Microbial Biotechnol. $35: 1503-1516$.

[7]. Ekundayo, E.O, Emede, T.O and Osayande, D.I (2010). Effects of crude oil spillage on growth and yield of maize (zea mays L.) in soils mid-western Nigeria. Plants, food and Human Nutrition, 56: 313-224.

[8]. Fleming, H. and Haselkorn, R. (1974) . The programs of protein synthesis during heterocyst differentiation in nitrogen-fixing bluegreen algae. Cell 3:159-170.

[9]. Haande S (2008). On the ecology, toxicology, and phylogeny of cyanobacteria in Murchison Bay of Lake Victoria, Uganda. Ph.D.Thesis, University of Bergen, Norway.

[10]. Jeganathan K (2006). Bioremediation studies on oil refinery industry effluent using Oscillatoria earli Gartner. M.Phil. dissertation. Bharathidasan University. Tiruchirapalli.

[11]. Kalavathi F.D, Uma 1, Subramaniam, (2001). Enzyme Microb. Technol. 29, 249 - 251.

[12]. Larsson P, Kizito YS, Miyingo-K A, Luyiga S, Haande S, Semyalo RP, Asio SM, Odong R, Lyche-SA, Brettum P (2009). Development in Murchison Bay. In: Larsson P, Kirumira E, Steigen AL, Miyingo-KA (Eds.). Sharing Water: Problems, Conflicts and Possible Solutions-the

[13]. Case of Kampala. Universitets for laget, Oslo. 221-230.

[14]. Margesin, R. and Schinner, F. (2001) Biodegradation and bioremediation of hydrocarbons in extreme environments. Appl. Microbiol. Biotechnol. 56:650-663

[15]. Megharaj, M., Singleton, I., Mc Clure, N.C., Naidu, I. R. (2000) Influence of petroleum hydrocarbon contamination on microalgae and microbial activities in a long-term contaminated soil. Arch. Environ. Contam. Toxicol. 38: 439-445.

[16]. Murugesan S, Sivasubramanian V (2005). Cyanobacteria of Porur Lake.Chennai. Tamilnadu. Indian Hydrobiol. 8(1): 49-54.

[17]. Olsen, S.R., Sommers, L.E. (1982) Determination of available phosphorus . In " Method of Soil Analysis", $2^{\text {nd }}$ edition .American Society of Agronomy.

[18]. Pearl, H.W, and Paul, V.J (2012).Climate changes- link to global expansion of harmful Cyanobacteria. Water research, 46 (5), 1349 $-1363$.

[19]. Podda F, Zuddas P, Minacci A, Pepi M, Baldi F.(2000). Heavy metal co-precipitation with hydrozincite $\left[\mathrm{Zn}_{5}\left(\mathrm{CO}_{3}\right)_{2}(\mathrm{OH})_{6}\right]$ from mine waters caused by photosynthetic microorganisms. Appl. Environ Microbial. 66(11): $5092-5098$.

[20]. Sorkokh, N., Al-Hasan, R., Radwan, S. and Hopper, T. (1992). Self-cleaning of the Gulf. Nature: $359,109$.

[21]. Subramanian, G., Sekar, S. and Sampoornam, S. (1994).Biodegradation and Utilization of organohosphorus pesticides by cyanobacteria.International Biodegradation and Biodeterioration 33, 129 - 143

[22]. Singh, P.K. (1973). Effect of pesticides on blue-green algae.Archives of microbiology 98, 317 - 320.

[23]. Tayade, S., Patel, Z.P., Mutkule,D.S, Kakde ,D.S A.M (2013). Pesticide contamination in food: A review. IOSR J. Agri Vet. Sci., 6(1): $7-11$.

[24]. Tsien,R.Y.(2003) Imagining imagings future. Nature Reviews Molecular Cell Biology 4: SS16- SS21

[25]. Venkateshwarlu, V (1976). Taxonomy and ecology of algae in the river Moosi. Hyderabad (India). Nova Hedwigia, 27: 661-676.

[26]. World Health Organization (2004). Guidelines for Drinking water Quality. $3^{\text {rd }}$ edition. Recommendations, 1:210-220.

[27]. Yoo, S., Carmichael, W., Hochn,R., Hrudey, S. (1995). Cyanobacterial (blue green algal) toxins: A resource guide. Denver ,CO, American Water Works Association Research Foundation,229.

Williams, Janet Olufunmilayo. "Remediaton of pesticide-polluted River using Anabaena and Nostoc spp." IOSR Journal of Environmental Science, Toxicology and Food Technology (IOSRJESTFT) 11.7 (2017): 71-76. 